\title{
UNA SEPARACIÓN ARTIFICIAL: GRUPOS YUMANOS DE MÉXICO Y ESTADOS UNIDOS
}

\author{
Por \\ Miguel Wilken Robertson *
}

\begin{abstract}
RESUMEN
Los grupos indígenas sobrevivientes de Baja California están vinculados estrechamente por lazos de lengua, cultura e historia con los grupos indígenas del sur de California y Arizona; todos estos grupos integran la región yumana. Este artículo examina la importancia de cada uno de los grupos yumanos bajacalifornianos dentro del contexto de la región como una totalidad, en lugar de separarlos arbitrariamente en yumanos mexicanos y estadounidenses. Se analizan algunos de los elementos paralelos de la tradición oral de los kumiai, paipai, kiliwa, cucapá, yavapai y hualapai, mostrando que un acercamiento comparativo transregional puede arrojar nuevas luces en el campo de la investigación de la historia antigua de los yumanos.
\end{abstract}

\begin{abstract}
The surviving indigenous groups of Baja California are closely linked through ties of language, culture and history to indigenous groups of Southern California and Arizona. This paper examines the importance of each of the Baja California Yuman groups within the context of the region as a whole, rather than arbitrarily separating them into U.S. and Mexican Yuman groups. Parallel elements in the oral traditions of the various groups are explored, showing that a trans-regional comparative approach may shed new light on the ancient history af the Yuman people.
\end{abstract}

Unidos por ancestros en comúm, divididos por la frontera.

Mucho antes de que existiera una división política entre Estados Unidos y México, los grupos aborígenes sobrevivientes de Baja California compartían lazos estrechos con los indígenas nativos de California y Arizona. Estos grupos, unidos por lenguas y formas de vivir similares, en su conjunto forman la región yumana, un área que se extiende desde las costas, desiertos y montañas del norte de Baja California y sur de California, a lo largo del Río Colorado, hacia el norte a través del Gran Cañon e

* Director de Culturas Nativas (CUNA), una organización para apoyo a las comunidades autóctonas de Baja California. 
incluyendo gran parte de la región occidental de Arizona (ver figura 1). La frontera internacional, de creación relativamente reciente y que separa a los yumanos mexicanos de los de Estados Unidos, estableció una division artificial entre estos grupos relacionados, así como una confusión en la literatura tocante a su historia común.

Este trabajo ofrece una sfntesis de evidencia que proviene de los registros arqueológicos, etnográficos y lingüísticos, asf como datos que vienen del trabajo de campo del autor entre los paipai y otros grupos yumanos que ilustra la relación sui generis que tienen en común cada uno de los sobrevivientes de los grupos nativos de Baja California con sus vecinos del norte.

\section{LA HERENCIA YUMANA}

La pregunta sobre cuándo llegaron por primera vez a la península los ancestros de los indígenas sobrevivientes aún no es clara. Los primeros investigadores tales como Malcolm Rodgers estimaron su ingreso entre 1,000 (citado por Bendímez, 1985:85) y 2,000 años (Owen, 1962:1). Moriarty (1966:20-30) propone 2,000 a 3,000 años de habitación por grupos yumanos, mientras que Laylander (1985:5) al citar evidencia lingüística propone un arribo temprano hace 6,000 años a la porción norte y centro de la peninsula de hablantes del Hokano quienes posteriormente se divergirian en grupos Yumanos y Cochimí.

Como otros grupos anteriores a ellos estos antiguos yumanos se encontraron en una de las regiones más aisladas del continente, rodeados en todas direcciones menos el norte por el mar. Mientras, quizá hubo contacto ocasional con gente del Pacífico (Hovens, 1991) o con grupos de tierra adentro de México (Kowta, 1984), la mayoria de la evidencia arqueológica y etnografica señala las fuertes conexiones con el macizo continental más allá de la boca de la península.

Ya que la única conexión con el continente es el sur de California, la península, obviamente, refleja una prehistoria y etnohistoria que recae a través de la información arqueológica y etnográfica dirigida del norte (Massey, 1966).

Miguel León Portilla describe las primeras migraciones de los grupos indígenas hacia la península como una serie de oleadas de penetración de grupos portadores de elementos propios de los pobladores prehistóricos del sur de Alta California y del suroeste de Arizona y de la cuenca baja del Río Colorado. Algunos de estos últimos (los cucapa) practicaban ya la agricultura desde el siglo vIII D.C., y producfan cerámica (León Portilla, 1987). 
MIGUEL WILKEN ROBERTSON

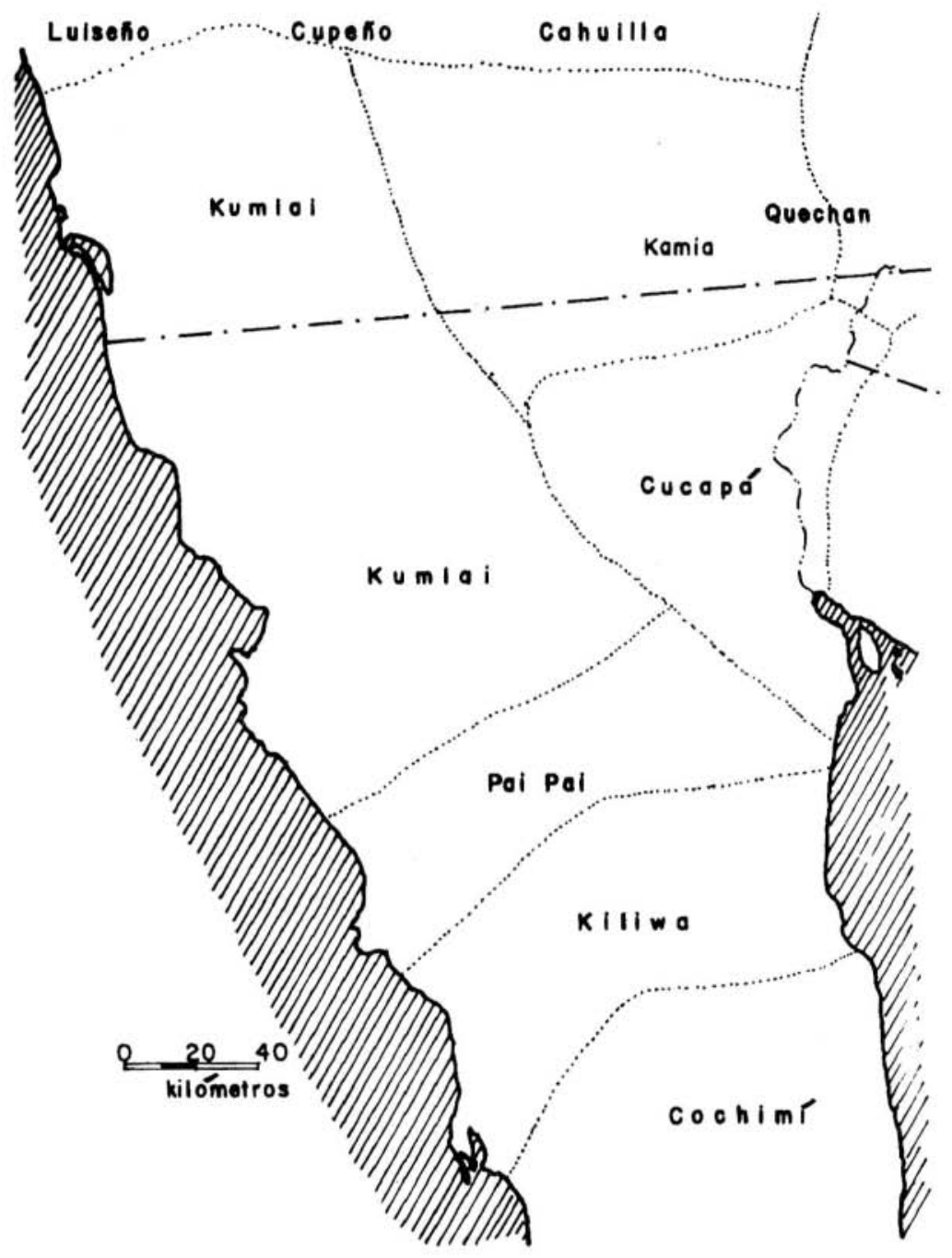

Figura 1. Distribucion de etnias yumanas previo al contacto misional. 
El complejo arqueológico yumano fue documentado a gran detalle por Malcom Rodgers, quien también realizó investigación pionera en la historia antigua de Baja California, Arizona y sur de California. Rodgers (1945 y 1966) describió la migración de gente yumana (a veces denominados patayan) a Baja California basándose en evidencia arqueológica y etnográfica. Otros investigadores que han indagado sobre las raíces de los grupos yumanos de Baja California incluyen a Aschmann (1966), Massey (1966), Álvarez (1975), Laylander (1985) y Bendímez (1985).

La tradición de cerámica yumana es uno de los elementos culturales diagnósticos más importantes y común en la arqueología de toda la región. Aunque la forma específica de la cerámica varía de acuerdo con los tipos de recursos utilizados, la pala y yunque yumanos y las formas básicas de los recipientes reflejan una tecnología y estética que parece haberse originado en la zona del Río Colorado y extendido entre los grupos yumanos de Arizona, Baja California y California (Rodgers, 1936; Van Camp, 1979). Hoy día, la tradición de cerámica es llevada a cabo por los paipai y kuatl (kumiai) de Baja California (Wilken, 1987).

Mientras que la migración a la península ha sido primordialmente de norte a sur, la comunicación entre las sociedades de la península y sus vecinos norteños ha sido, desde hace mucho, multidireccional. Estudios arqueológicos documentan las rutas de trueque antiguas tanto de las costas del Pacífico como del golfo de California, arriba hacia la cuenca del Río Colorado y más allá de esa zona (Rodgers, 1966), Laylander señala que las excavaciones en la zona yumana occidental demuestran que:

... la ocurrencia de materiales, incluyendo roca volcánica y concha marina... sugieren uso rutinario de recursos moderadamente; estudios de la regionalmente exótica obsidiana, sugieren adquisiciones a través de intercambio durante las congregaciones estacionales de varios grupos diferentes de todas las regiones en arcas de tierras altas (Laylander, 1991:56).

Obsidiana que al parecer es de bancos ubicados al sur de San Felipe a menudo se encuentra en excavaciones del sur de California (Laylander, 1993). El registro etnográfico documenta, también, trueque entre los grupos yumanos de las montañas del norte de Baja California con sociedades del delta del Río Colorado, "Intercambiando productos agrícolas por alimentos silvestres cotizados, tales como la bellota y la nuez del pino piñonero" (Bendímez, 1987). Claramente se puede decir que el contacto entre estas sociedades a través de los milenios se ha basado en consideraciones geográficas y culturales, y sólo en el último siglo y medio es que la división política entre los Estados Unidos y México empezó a separarlos. 


\section{NKXOS CULTURALES Y LINGÜÍSTICOS}

A través de la región yumana, cazar y recolectar flora silvestre, ha sido In estrategia de sobrevivencia más importante. Comunidades que podían contar con agua suficiente, especialmente aquellos que vivían a lo largo del Río Colorado y el Gila, también practicaban diversas formas de agricultura y desarrollaron asentamientos más permanentes (Hinton, 1984:5). Quienes dependían únicamente de la recolección de alimentos silvestres desarrollaron una forma de vida de gran movilidad, seminómada, basada en los ciclos de explotación de recursos de temporada a través de un territorio específico, generalmente rodeando una "base hogar" (Michelsen, 1991:153). Algunos grupos, tales como los kumiai, desarrollaron, de acuerdo con Florence Shipeck (1989), formas de "manejo" de plantas silvestres, mientras que aquellas sociedades con acceso a zonas costeras cosechaban recursos marinos.

Cada uno de los grupos marinos desarrolló su lenguaje y forma de vida particular; sin embargo, detrás de esas diferencias existen patrones comunes que han evolucionado a partir de sus historias compartidas. En el caso de los grupos yumanos de Baja California, cada uno tiene una relación especial con grupos yumanos al norte de la frontera, algunos con vínculos muy antiguos (los kiliwa), otros con una historia común más reciente (los paipai) y algunos cuyos territorios y lenguajes aún forman un continuum (los kumiai y cucapá) a pesar de su separación por la frontera internacional.

Los kiliwa o kolew, como se llaman a sí mismos, habitaron originalmente un amplio territorio extendiéndose del golfo de California, a través de la sierra de San Pedro Mártir — la más alta de Baja California-, hasta la costa del Pacífico en el área de lo que ahora se llama San Quintín. Su localización es geográficamente la más austral de todos los grupos indígenas sobrevivientes de la península.

El kiliwa parece ser una de las primeras lenguas yumanas en separarse de la raíz proto yumana (Laylander, 1985:26) y la rama más divergente de la familia de lenguas yumanas (Mixco, 1977:167). Como el grupo sobreviviente más aislado de la región yumana, los kiliwas conservan elementos lingüísticos y culturales que se fechan hasta los orígenes de todos los grupos yumanos.

El texto siguiente del kiliwa Rufino Ochurte demuestra un conocimiento de la tradición oral del los enlaces norteños del grupo.

La gente migraba del Norte, vinieron en esta dirección. Llegaron aquí.

Llegaron y se pararon a mirar. El chamán estaba cantando una oración.

El mar se retiró y empequeñeció, todavía está así. Cruzaron y vagaron, 
viniendo, viniendo, viniendo a cierto lugar distante llamado "agua atrás de la montaña". Cuando llegaron allá el chamán estaba cantando. Los oí decir que era de esta manera, se dice que la gente migró de la montaña más grande y más alejada en la Tierra. Vinieron de ahí y viajaron aquí, a Xpuq (paso de San Matías), ahí acamparon. Entonces ellos migraron de ahí y empezaron a dispersarse sobre la Tierra... (Mixco, 1983).

El texto contiene muchas pistas de la historia antigua del grupo. El "mar que se retiraba" puede referirse al Lago Cahuilla, el gran lago interior que durante varios periodos de la historia antigua se extendía desde el Mar Salton en el sur de California a la Laguna Salada en Baja California, proveyendo a los tempranos grupos indígenas con un abundante ambiente para vivir. La gran montaña mencionada en el texto se ajusta a la descripción hecha por muchos otros grupos yumanos del sitio sagrado de origen, Wi Kahme o Spirit Mountain en Nevada. A pesar de los cientos o quizás miles de años de separación de sus vecinos al norte, los kiliwa todavía conservan el conocimiento de su antigüedad común.

\section{LOS KUMIAI Y CUCAPÁ-YUMANOS DEL DELTA-CALIFORNIA}

Ambas lenguas kumiai y cucapá pertenecen al subgrupo delta-california de la familia de lenguas yumanas. Los territorios ancestrales, tanto de los kumiai como de los cucapá, han sido disectados por la frontera México-Estados Unidos, resultando en una divergente evolución de las culturas de los grupos, dependiendo del sitio donde cayó en su territorio la división política. Estos grupos divididos nunca perdieron contacto completamente con sus parientes del norte, sin embargo, este contacto se ha hecho cada vez más difícil de mantener pues el libre movimiento de personas y bienes cada vez es más restringido. En general, puede decirse que los grupos del norte de la frontera han disfrutado los beneficios del desarrollo económico al costo de un más rápido proceso de aculturación por la sociedad dominante, mientras que los grupos al sur de la frontera han mantenido mucha de su cultura tradicional —uso de la lengua indígena, recolección de plantas alimenticias silvestres y la elaboración de artesanías, para mencionar algunas - mientras permanecen marginados económica y geográficamente de la sociedad dominante.

El territorio kumiai comprende una extensa área que incluye la mayor parte del condado de San Diego al sur de Escondido, California y el oeste del condado Imperial hacia el sur a aproximadamente la misma latitud hasta a algunas 60 millas al sur de la frontera internacional, con la escarpada este de la Sierra de Juárez formando el límite este con los cucapá. 
Dentro de este territorio se habla una lengua con muchas diferencias dialectales; desafortunadamente, los diversos términos usados para la lengua o para designar distintos dialectos frecuentemente causan confusión o crean la impresión de lenguas o grupos tribales distintos. Esta lengua es frecuentemente llamada diegueño o kumiai por los hablantes nativos. En un examen de la organización comunitaria de los grupos yumanos occidentales, Laylander explica que:

El término diegueño aparece con relación a la Misión de San Diego de Alcalá. Algunos autores dividen el diegueño en diegueño del sur, diegueño del norte y diegueño del oeste, y a su vez otros subdividen el diegueño en ipai y tipai. Además de lo anterior, es necesario aclarar que la lengua kwal y kamia pertenecen a este grupo lingüístico. La antropología en Baja California ha considerado el término kumiai representativo de estas distintas nomenclaturas (Laylander,1991: 32).

El territorio cucapá, por lo menos durante los últimos 400 años, incluía el bajo delta del Río Colorado, el Río Hardy y las bajadas de la sierra Cucapá, aunque en épocas más remotas es probable que los ancestros de los cucapá, como los de otros grupos yumanos, vivieran a lo largo de las costas del Lago Cahuilla. Álvarez reporta que un anciano cucapá le dijo que "existe la tradición entre su gente de recordar los tiempos cuando la sierra Cucapá era una península con un gran lago de agua dulce bañando sus bajadas" (Álvarez, 1987).

Desafortunadamente la reducción y devastación ambiental del territorio original cucapá dejó a los habitantes nativos con sólo unos cuantos asentamientos, algunos al norte y algunos al sur de lo que es actualmente la frontera internacional. Colonizadores no indígenas expropiaron la mayoría de las tierras ancestrales cucapá, "tomando decisiones políticas que dividieron a los cucapá, dando por resultado que algunas familias permanecieran en Estados Unidos y otras en México" (Álvarez I., 1978).

\section{LA FAMILIA PAI}

La lengua Paipai pertenece a la familia pai de las lenguas yumanohokanas que incluye el yavapai, el hualapai y el havasupai de Arizona. Estas tres últimas lenguas pai y sus varios dialectos fueron hablados en una gran área de lo que es ahora el oeste de Arizona, formando una gran área de cultura pai desde el Gran Cañón hasta el sur de Arizona hacia el Río Gila. El paipai, por otro lado, representa una isla intrigante de la cultura pai en Baja California, aislada de los hablantes pai de Arizona por grupos yumanos más lejanamente emparentados. Cómo y cuándo esta rama de la 
familia pai vino a habitar una extensa área del norte de Baja California - de la boca del Río Colorado a través de la Sierra de Juárez y hasta el Pacífico- permanece aún incierto.

Nadie sabe desde cuando han estado los paipai en la Baja California Norte. Por su parentesco cercano con los idiomas Pai de Arizona...se les supone de origen norteño relativamente recién entre las comunidades yumanas de la península (Mauricio Mixco, en Hinton, 1984).

Sin embargo, la hipótesis de origenes norteños no es la única posibilidad. El paipai Benito Peralta, reconocido como un historiador de su tribu (ver Bendímez, 1989) recuerda: "mi tío siempre me deć́a que el verdadero paipai se encontraba en el norte," apuntando con el dedo hacia el noreste, "pero lo que yo quisiera saber es si ellos salieron de aquí y fueron para allá o si nosotros salimos de allá y llegamos aquí." (Wilken, notas de campo, 1992). Haciendo eco a esta inquietud, Laylander sugiere otras dos hipotesis: un movimiento paipai del norte de Baja California hacia Arizona occidental, o una migración intrusiva por grupos kumiai, cucapá y/o quechanos ahora separándose de Arizona y miembros de la familia pai de Baja California (Laylander, 1985:35).

\section{RECONSTRUYENDO LA HISTORIA PAI. UNA PERSPECTIVA NATIVA}

Es necesario investigar más para determinar las raíces de la presencia paipai en la península, sin embargo, una observación de semejanzas lingüísticas combinada con evidencia etnográfica revela un sorprendente parentesco cercano entre los grupos pai de Baja California y Arizona. Por ejemplo, las lenguas pai de los Estados Unidos y de México son casi idénticas cuando los temas son los elementos básicos de su ambiente natural tales como agua, tierra, alimentos silvestres, plantas y animales (Wilken, notas de campo, 1993). Esas extraordinarias similitudes entre las lenguas y otros aspectos de la cultura pai en ambos lados de la frontera no sólo han fascinado a los académicos, también han intrigado a los mismos indígenas, quienes en los años recientes han estado restableciendo contacto para encontrar las piezas perdidas del rompecabezas.

Desafortunadamente para los paipai, el acceso a los parientes norteños ha sido prácticamente imposible debido por una parte, a la dificultad para obtener documentos para cruzar la frontera internacional, y por la otra, a los gastos que implica para sus comunidades viajar a los Estados Unidos. Así, hasta 1992, los pocos contactos que se habían hecho fueron de miembros individuales de las tribus pai de Arizona que visitaban Santa 
Catarina, el asentamiento paipai más grande. Entonces, en el verano de 1992, varias delegaciones de las tribus Pai de Arizona asistieron al primer festival anual de música y danza tradicionales en la comunidad paipai donde encontraron que tenían mucho en común: lengua, canciones, estilos de danza, tradición oral y hasta sorprendentes similitudes en la flora, fauna, geografía y clima de sus territorios.

Como resultado de esta reunión, varios de los ancianos paipai fueron invitados a visitar las comunidades yavapai y hualapai. Se organizo un viaje por el Instituto de Culturas Nativas con el apoyo del Instituto Nacional de Antropología e Historia y el Instituto Nacional Indigenista, así como con la colaboración de las comunidades pai de Arizona. En el siguiente año y medio se realizaron tres viajes más, cada uno ayudó a los indígenas a reconstruir su propia historia y a reforzar los antiguos nexos entre sus gentes.

Quizá uno de los aspectos más productivos de estas reuniones ha sido el compartir sus historias, mitologías y cuentos acarreados en la memoria colectiva; lo que dio luz sobre como las tribus conciben su propia historia. Por ejemplo, entre la gente pai existen varias formas de tradición oral que explican como los paipai llegaron a habitar Baja California.

Curiosamente, los paipai aparentemente tienen pocas explicaciones detalladas sobre su propio origen, aunque parece haber un recuerdo de movimiento desde el noreste. El anciano paipai Pedro Castro le dijo a sus niños, "nuestros ancestros vinieron de donde sale el sol" (Wilken, notas de campo, 1980), y Benito Peralta se refiere a un ser creador que vino del noreste de tierra paipai histórica:

Cruzaron a esta tierra, al desemboque [del Colorado] al aguaje detrás del cerro [que le dicen]. Allí se puso a cantar [Dios] acomodando las razas en sus hogares. Estuvo nombrando los apellidos de cada pueblo, en su aguaje (Mixco, 1977:216-217, citado en Bendímez,1989).

Entre los grupos pai de Arizona, la memoria de una migración del suroeste toma diferentes formas. La yavapai Esther Scott, hablante del dialecto yavpe o yavapai noreste, cuenta la siguiente historia que le fue dicha por el jefe heredero Grace Jimulla Mitchell.

La gente vieja de nuestra tribu decía una historia sobre un grupo que se separó del nuestro hace mucho, mucho tiempo. Todo empezó porque había una joven pareja que se enamoró, pero la tribu no podía permitir que se casara porque eran primos. Así que fueron corridos, pero algunos de sus parientes fueron con ellos porque sabían que la joven pareja se encontraría con una muerte segura si eran dejados solos. 
El grupo vagó por todo el bosque hasta que llegaron a la tierra de los Hualapais. Se les permitió quedarse por un tiempo, el suficiente para que el nuevo grupo se mezclara y hasta se casara con los Hualapais. Pero eventualmente los Hualapais tuvieron que pedirles que se fueran porque se dieron cuenta que la presencia del nuevo grupo podia provocar la guerra con los Yavapai.

Así que el grupo se encaminó hacia el oeste hasta que llegaron a las tierras de los indios Mojave. Otra vez se les permitió quedarse por un tiempo, mezclándose con los Mobave y quizá casándose, pero eventualmente les pidieron que se fueran por temor a represalias de los Yavapai.

Finalmente llegaron al Río Colorado, donde construyeron un bote y navegaron por el rio hacia el sur. Eso fue lo último que supimos hasta hace unos años, cuando oímos que había un grupo de indios en las montañas de Baja California que casi hablan el mismo lenguaje que nosotros (Wilken, 1992:31-32).

Un cuento similar fue recolectado de los yavapai del sureste, quienes describieron a la pareja como "un muchacho y una muchacha muy bellos que vinieron de las montañas superstición" (Wilken, notas de campo, 1993). Ninguno de los informantes estaba seguro de cuándo tuvieron lugar los eventos descritos, pero ambos coincidieron en que fue probablemente antes del contacto con las culturas europeas. La historia también refleja los tabús sobre el incesto de la cultura tradicional yavapai, aunque debe señalarse que dos héroes de la cultura yavapai también estuvieron involucrados en incidentes de incesto, entre parientes aún más cercanos.

De acuerdo al mito del origen yavapai Komwidapokwia, la primera mujer fue inseminada por el sol y gotas de agua de manantial. Cuando su hija creció, su madre la instruyó para que se inseminara de la misma manera. Sin embargo, el sol y el manantial se rehusaron a entrar en la muchacha porque se daban cuenta que era su propia hija, asi que la madre los engañó para inseminar a su hija acostándose arriba de ella. El resultado de esta unión fue el gran héroe de esa cultura Skaraka'amsha, el asesino de monstruos y primer chamán.

La violación del tabú de incesto también figura en muchas versiones de la mitología del origen pai en los que el primer jefe, el que crea o pone orden en el mundo, enferma y muere como resultado de relaciones incestuosas con su hija (Gifford, 1933:402; Khera, 1979:40).

La historia de los primos revela muchos niveles de significado simbólico. Sin embargo, puede ser también como un recordatorio literal de la historia, especialmente considerando que una balsa flotando Rio Colorado abajo vendría al golfo de California justo en el punto donde el territorio 
ancestral paipai empieza. Muchos ancianos yavapai también se refieren a los paipai como Aha Bawamma Abaaja, "las gentes que fueron arrastradas por el río", tanto refiriéndose a la historia de los primos, o explicando que en una gran inundación donde se perdió mucha gente, algunos pueden haber sobrevivido y terminado río abajo en Baja California.

Entre los hualapai existen varias explicaciones de como llegaron a vivir los paipai a Baja California. Muchos apuntan al primer mundo cuando los dos hermanos dioses-creadores que vivían en la Spirit Mountain estaban enviando a los grupos en diferentes direcciones.

Pero el momento llegó cuando había mucha gente para ser soportada por la tierra, y ellos empezaron a tener problemas entre diferentes clanes. Los problemas empezaron con los niños, cuyos juegos de guerra con bolas de lodo se volvían fieros cuando empezaron a poner espinas de cactos y pedacitos de piedras filosas en las bolas. A medida que se lastimaban, los padres intervenían en los conflictos y empezaban a pelear entre ellos. Las peleas escalaron hasta guerras formales entre los diferentes grupos hasta que el jefe los tenía que separar.

Cada grupo fue enviado a un área diferente de acuerdo a sus talentos especiales - algunos para ser agricultores y sembrar maíz-, algunos para ser cazadores y algunos (los Hualapai) para ser corredores. Un grupo fue enviado a la tierra que ahora es llamada Baja California (Wilken, 1992:32).

Cuando la delegación paipai visitó a la comunidad hualapai en Peach Springs, Arizona, muchos hualapai describieron la marcha a la que fueron forzados sus padres y sus abuelos hacia el sur a un campo de concentración en el condado La Paz, Arizona durante la década de los ochenta del siglo pasado. Ellos sugieren que los paipai pueden ser descendientes de algunos de los hualapai que escaparon y de los que no se volvió a oir. Sin embargo, esto parece una explicacion improbable pues se sabe que los paipai habran vivido en Baja California mucho antes de esa época. Claramente la historia oral y la memoria histórica no pueden ser considerados recuentos históricos infalibles, así como la sola evidencia arqueológica, lingüística y etnográfica puede ser equívoca. No obstante, las perspectivas de los grupos nativos proveen claves vitales que son invaluables en la reconstrucción de miles de años de historia indígena.

\section{PATRONES REGIONALES EN LA MTTOLOGÍA YUMANA DEL ORIGEN}

Cada uno de los diferentes grupos yumanos ha desarrollado su repertorio separado de mitos, leyendas, cuentos, historia y canciones en 
respuesta a su suelo, historia y al talento de los que transmiten la tradicion oral. Muchas canciones y cuentos se refieren a características geograficas especificas dentro o cerca del territorio de algún grupo, o bien, representan una remembranza de hechos y eventos que han ocurrido en ese territorio. Otras reflejan la vívida imaginación de los cuenta cuentos, cantantes y soñadores de la tribu, o la influencia de culturas vecinas de tradiciones lingüisticas no relacionadas.

No obstante, ciertos temas subyacentes surgen repetidamente entre todos o la mayorfa de los grupos yumanos, especialmente en la más antigua de las manifestaciones de la tradicion oral: leyendas y mitología del origen. Mientras que existen claras variaciones localizadas, una comparación de mitologías de origen de grupos yumanos tanto al norte como al sur de la frontera revela claros patrones arquetípicos comunes a la región entera. Una composición de esos motivos podría verse como lo siguiente: 1) De bajo el agua o bajo la tierra, los primeros creadores emergen. Ellos son usualmente dos varones emparentados y uno es frecuentemente ciego o incapacitado; 2) Crean cosas e intentan poner el mundo en orden; 3) Hay una jerarquía entre estos dos creadores, y exhiben muchas cualidades humanas; 4) El creador más viejo muere y es cremado. Durante la cremación, Coyote se roba el corazón y se lo come.

Esos detalles generalmente aparecen más precisos y como parte de una narración más larga, pero debido a su amplia distribución y notable similitud, han sido escogidos con el proposito de comparación. En la sección siguiente, cada uno de los detalles de arriba (organizados aquí por número) serán comparados entre las mitologías de los diversos grupos yumanos de Baja California y su contraparte en Estados Unidos.

1) De bajo las aguas o bajo la tierra, los primeros creadores emergen. Son usualmente dos varones emparentados, y uno es frecuentemente ciego o incapacitado. De acuerdo con un mito de la creación kumiai recolectado por Malcolm Rodgers:

Al principio no había tierra, sólo agua por todos lados, pero bajo el agua había una cueva en la que vivian dos bermanos. Ambos habian estado allí durante larguísimo tiempo, ¡desde siempre! parecía. Un día el mayor dijo al bermano menor. debemos subir basta la superficie, y ver lo que hay arriba..nadó hacia la superficie llevando los ojos cerrados para que el agua salada no se los lastimara. Cuando el hermano menor subió a la superficie...se había quedado ciego, porque llevó abiertos los ojos. (Rodgers, en Álvarez, 1975:62-64).

El antropólogo William Kelly registró un mito cucapá de la creación en los años cuarenta, que empieza: 
Sipa y Komat, los dioses creadores, estaban bajo el agua y la tierra, viviendo en la forma en la que vive un niño en su madre. Toda la tierra estaba cubierta de agua. Empezaron a bablar de salir a la superficie. Estos dos creadores eran primos (kawak). Cuando subían por el agua, Komat le preguntó a su hermano que cómo le había hecho y Sipa le contestó que abrió sus ojos. Cuando el hermano mayor abrió los ojos en el agua fue cegado. (Kelly, 1977, en Bendimez, 1991:76).

\section{Una versión del mito hualapai del origen explica:}

Una vez todas las tribus indígenas se habían ido, hace mucho, mucho tiempo. En este tiempo hubo dos dioses, Hama'tavila...el mayor y Tu'djupa, el menor. En el oeste hay una montaña, Wikame, que se encuentra sola. Wikame fue formada cuando el agua se secó a través de un hoyo en el suelo ... de bajo Wikame los dos dioses aparecieron, y subieron a la cima y se sentaron ahí (Kroeber, 1935:12).

Wi Kahme, o montaña del espíritu, a veces conocida como "la sierra montaf̂osa más alta" (Hinton, 1984:3) es un lugar sagrado para todas las tribus yumanas. Aunque está localizada en Nevada, lejos del territorio de los grupos yumanos de Baja California, tiene un lugar importante en la tradición oral de cada uno de esos grupos.

La mitología yavapai está especialmente ligada a la geografía sagrada de su territorio ancestral, comoen el caso de los yavapai del Oeste para quienes el hoyo a través del cual la gente emergía es una formación geológica especifica ahora llamada pozo de Montezuma cerca de Sedonna, Arizona.

La gente bajo la tierra era humana. Ahí vivian dos bermanos - uno viejo y uno joven. Ellos vivian en la casa de tierra. Reunieron un consejo sobre cómo subir al mundo superior. El hermano joven era el lider y el planificador. Así que plantaron un abeto y uva silvestre juntos de tal manera que la vid se enredaría en el tronco que crecia. Crecieron en poco tiempo a través de un hoyo en el cielo del mundo inferior. La gente llegó con seguridad al mundo superior... (Gifford, 1933:402. 403).

El paipai Benito Peralta recuerda diversos cuentos completos y fragmentos de cuentos (en vez de un solo mito de la creación) que contienen elementos similares a los descritos arriba. "Estos eran tres sabios que venían del sur. No me acuerdo cómo el más poderoso de ellos se había quedado ciego en el camino. Venian caminando, creando cosas." (Wilken, notas de campo, 1990). 
En este caso el número de creadores son tres en vez de dos. Han venido del sur en vez de bajo tierra, sin embargo Peralta enfatiza que este es sólo un fragmento de un cuento mucho más largo así que pudo ser originalmente una emergencia del subsuelo, como en el siguiente fragmento kiliwa de la creación narrado por el kiliwa Rufino Ochurte: "Persona-tierra creó cosas. El vino de debajo del suelo [salió]. Tres hombres [salieron también]. Se sentaron en un círculo. Se sentaron y sentaron. Estaban creando cosas." (Mixco, 1983).

Una versión diferente narrada por el kiliwa José Espinoza ubica el centro de emergencia en territorio ancestral kiliwa. "Metipa, el creador, salió de debajo de la tierra en un paso. Surgió de debajo de la tierra detrás de una pequeña montaña roja, Wey cojan, 'cerro bueno'." (Meigs, 1939, citado en Bendímez, 1991:79).

El primer acto de Metipa de creación es el hacer sus cuatro hijos, uno de los cuales se vuelve su cocreador. Como en el cuento paipai, hay más de dos creadores, sin embargo, la mayoría de el trabajo está hecho por dos deidades sorprendentemente humanas.

2) Hay una jerarquía dentro de estos dos creadores, y muestran muchas cualidades humanas.

Los creadores exhiben atributos tanto divinos como humanos, frecuentemente cometiendo errores que deben ser rectificados o que deben tener impacto duradero en la humanidad. La diferencia de edades entre los dos juega un papel importante en el desarrollo del cuento, y como los demás hermanos, no siempre están de acuerdo en todo.

En la versión hualapai de Paul Talieje, los hermanos se llevan milagrosamente bien. Después de que un primer ciclo se termina por una gran inundación, el cuidador del universo crea dos hermanos:

En verdad, un Hermano-tierra menor y un mayor Hermano-tierra, dos seres que él creó.

Estos dos seres ellos fueron los primeros.

Ése, ligeramente mayor, el auxiliar de el Viejo, ese, su nombre Madvil, se llamaba...

El hermano menor de ése era llamado Judabah;

De alguna manera estos dos vivían ahí, así que sucedió así, así sucedió.

Después de crear humanos y ordenar el mundo, él declara:

Entonces así será; mi hermano te guiará...

Cuando yo me haya ido, cuando me vaya, él se hará cargo y vivirá aquí, así dijo. (Hinton, 1984:20-27). 
En una versión diferente de el mito hualapai el hermano menor asume poder al determinar que el hermano mayor es incapaz.

El hermano menor le dijo al mayor, "¿Sabes todas las cosas?"

Pero el mayor respondió, "Soy muy viejo. No sé nada. Tú eres joven, tú debes hacerte cargo y dirigir el mundo."

Tudjupa dijo, "Puesto que no sabes nada, yo dirigiré" (Kroeber, 1935:12).

Para los yavapai del oeste, la rivalidad entre hermanos llevó a la creación del sol. Cuando los hermanos aún vivían bajo la tierra, el hermano menor le dijo al hermano mayor:

Yo pensé que tú eras un hombre sabio. ¿Por qué no iluminar las cosas con un sol, pues donde estamos viviendo bajo la tierra siempre está oscuro? ¿Por qué no hacer un mundo más brillante?

El hermano mayor, como era llamado el hombre sabio, dijo:

Sí. Yo proclamo ser un hombre sabio. ¿Y qué? ¿Y qué? Entonces se levantó de su cama y con cal húmeda redondeó algo. Entonces embarró un lado con pintura roja para dar luz. Entonces se estiró hasta el techo del inframundo y lo pegó ahí, donde daba una luz tenue. El hermano menor no gustaba de la luz tenue y dijo: Bueno, pensé que eras más sabio. Veo que no eres muy sabio. Veo que te falta inteligencia. Entonces el hermano menor hizo un disco de cal y le embarró pintura roja. Lo pegó al techo igual que el anterior. Este dio mejor luz para que la gente pudiera ver. Era mucho más brillante.

El hermano menor le dijo al otro que el suyo era mejor, porque daba más calor. El calor casi derritió a la gente. Así que pensaron en una forma de hacer el lugar más frío. El joven le aconsejó al viejo que usara su bastón (dikeru) para elevar el techo del inframundo hasta que la temperatura fuera correcta. El hermano mayor hizo esto (Gifford, 1933:402).

La versión kumiai dice cómo el hermano mayor emergió de debajo de las aguas conservando sus ojos cerrados de tal manera que el agua salada no afectara su vista. Sin embargo, cuando su hermano le pregunta desde abajo cómo subir, el mayor a sabiendas causa la ceguera del joven cuando le dice:

Ven con los ojos abiertos, para que puedas ver donde estoy, repuso el hermano mayor maliciosamente, porque lo que quería era que el joven se dañara la vista para quedar él como el más fuerte y el de mayores bienes. Porque mintió él, mienten los seres humanos: es el principio de la falta de honradez en la humanidad (Álvarez, 1975:62-63).

El hermano mayor intenta engañar de nuevo al hermano menor, sustituyendo su tejón por la avecilla de su hermano. Sin embargo a pesar de su 
ceguera, el hermano joven se da cuenta de lo sucedido y regresa furioso a su cueva, donde sus movimientos causan temblores de tierra. En el mito cucapá, los efectos de la rivalidad descontrolada entre hermanos llevan a peores consecuencias. Otro aspecto curioso de esta versión es la inversión de la relación entre edades:

Komat fumó un cigarro para hacerse de fuerza adicional y porque él era el mayor empujó hacia afuera a Sipa. Cuando llegaron al exterior Komat se tornó el más joven y Sipa el mayor, porque Sipa salió primero (Kelly,1977).

Como en el otro mito kumiai, el hombre joven queda cegado cuando el hermano mayor le da instrucciones de abrir los ojos bajo el agua. El hermano mayor también intenta cambiar mascotas con su hermano ciego, quien de cualquier forma está al tanto del engaño. Haciendo gente de arcilla, Sipa trata de cambiar su gente por la que hizo su hermano, "porque eran mejores". Al principio el hermano joven no dice nada, pero finalmente se enoja tanto que rompe los cielos y se mete a la tierra, dejando un hoyo. Como resultado, "el humo, el aire, la electricidad y otras cosas que causan la muerte" escaparon al mundo.

Todos los mitos anteriores presentan deidades con personalidades separadas y con relaciones fraternales que varían de cooperativas a violentamente antagónicas. Sin embargo, subyaciendo estas diferencias existe un patrón claro: los primeros creadores, mientras que poseían la cualidad divina de crear cosas, también exhiben un comportamiento típicamente humano de hermanos competitivos, o por lo menos una clara relación jerárquica entre el hermano menor y el mayor. Bendímez, en un análisis de la mitología nativa Bajacaliforniana, señala que tanto en el mito kumiai como en el Cucapá uno de los hermanos asume el papel de líder y finalmente pone el mundo en orden.

Así en el mito cucapá de la creación, Komat crea hombres y da origen al sol pero no es él quien al desenvolverse más este génesis será el guardián de los primeros pasos de la humanidad sobre la tierra. ...Analizando bien el mito, Komat era más fuerte y tenía más habilidades y conocimientos que Sipa, sin embargo, éste venció por su fuerza de voluntad para sacar partido de las pequeñas ventajas. (Bendímez, 1991:80-81).

La lucha arquetípica por el poder entre hermanos parece notablemente familiar a una audiencia contemporánea, pero debe recordarse que estos mitos evolucionaban de una época y modo de vida extremadamente diferente al nuestro. En el contexto cultural de cazadores y recolectores 
que vivian en agrupaciones seminómadas de clan patrilineal (Michelsen, 1991), el comportamiento de los hermanos no solo explica la existencia de enfermedades y temblores, puede también revelar mucho sobre tensiones psicologicas y maniobras políticas en la vida diaria de las sociedades yumanas tempranas.

Como se menciona arriba, los fragmentos paipai y kiliwa de la creación involucran a un creador y a varios cocreadores, en vez de a dos hermanos. Sin embargo, el patrón básico otra vez es la base de esos detalles, el discurso toma la forma de un dueto entre "el más poderoso" y sus ayudantes, o entre el kiliwa "Persona-Tierra" Metipa y su hijo mayor. Además,' como otros dioses-creadores yumanos, sus intentos de creación son frecuentemente divertidamente imperfectos o requieren reparación.

3) Crean cosas e intentan poner en orden el mundo.

Los dioses-creadores se pusieron a trabajar creando tierras, océanos. cielo, sol y luna, animales y gente. En cada región los detalles particulares de la creación varfan tanto como las distintas lenguas y geografía de la región. Para los kumiai y los cucapá, la tierra está hecha por hormigas trabajadoras, para los kiliwa el cielo está hecho de la misma piel del creador, para los hualapai, los humanos fueron hechos de los carrizos y otros de arcilla.

Sin embargo, un examen cuidadoso de la creación del sol revela más patrones de elementos comunes. El mito yavapai del oeste, examinado en la sección previa, describe como fue formado el sol y colocado en el ciclo del inframundo. Entre los grupos yumanos de Baja California, la creación del sol es también de importancia primordial y toma una forma básica similar, aunque con las variantes esperadas. De acuerdo al mito yavapai del oeste, ambos hermanos hicieron el sol de cal embarrada con pintura roja, pero el sol del hermano menor dio más calor. En el mito kumiai, Tcipakomat trabaja solo, habiendo su hermano regresado a la tierra.

Luego Tcipakomat hizo luz, para lo cual cogió un puñado de tierra amarilla, la comprimió hasta hacer una pelota y la tiró al cielo donde se quedó, convirtiéndose en la luna. Pero aquella luz era muy pálida así que Teipakomat buscó tierra roja $\mathrm{e}$ hizo otra pelota que lanzó nuevamente al cielo y así formó el sol, que daba suficiente luz (Álvarez, 1975:63).

Aunque el primer intento de producir un sol falló, la luz pálida de la tierra amarilla se convertiria en la luna, como en el siguiente mito cucapá:

Todo era oscuro, de manera que Sipa intentó hacer un sol. Hizo uno muy pequeño, y la luz no era mejor que la de la luna. No le gustó a 
Komat, de manera que empezó a hacer un sol en etapas fáciles. Cuando hubiese terminado, aventó el sol bacia el este y después de eso éste viajó de este a oeste para que la gente supiera cuándo levantarse, cuándo trabajar y cuándo dormirse. Sipa iba a tirar su sol, pero Komat le dijo: No, deja que se quede, será la luna. La gente puede distinguir las temporadas, los meses y los dias por la luna. (Kelly, 1977).

Uno de los mitos kiliwas de la creación registrado por Meigs menciona una ubicación similar de una esfera en un patrón Este-Oeste, pero en este caso sí es la Luna.

Luego Metipa hizo la luna. La puso en el este. Menuikunama pensó que estaba mal colgado, así que se la llevó por el cielo y la colgó en el oeste. Así es de que la luna siempre se pone en el oeste. (Meigs, 1939:66-67, citado en Bendímez, 1991:80).

En este mismo mito y en otras versiones de los mitos kiliwa, paipai y kumiai, el sol se origina en el interior del cuerpo del creador.

Luego Metipa quería hacer el sol. Lo tenía en su estómago. Se lo sacó por la boca y lo puso en el cielo: pero estaba algo mal, de manera que se lo volvió a tragar otra vez. Luego intentó sacírselo vía sus genitales, pero no pudo, y lo volvió a colocar en su estómago. Luego trató de sacarlo por el recto y lo logró, colgándolo en el cielo en el este. Por este motivo la gente tiene rectos quemados. (Meigs, 1939:66-67. citado en Bendímez, 1991:80).

El origen del sol dentro del cuerpo del creador y sus intentos de extraerlo a través de diferentes partes de su cuerpo son temas repetidos, como en este fragmento de la creación narrado por el paipai Benito Peralta.

Entonces el más poderoso queria hacer el sol, nomás que lo hizo adentro de su cuerpo, en su estómago. Lo intentó sacar, intentó sacarlo por el ombligo, pero no pudo, nomás dejó la cicatriz. Entonces trató de sacarlo por las rodillas, pero tampoco. Luego intentó sacarlo por los nudillos de los dedos, pero no, nomás dejó la cicatriz. Por fin lo sacó por la boca, pero dejó los labios así quemados.

Ya que losacó, estaba alli, afuera, pero nadie se arrimaba, hacía mucho calor. Lo querian subir pero no hallaban cómo. Hasta que la vibora lo subió, poco a poco lo iba subiendo con el cuerpo. Por eso la víbora tiene líneas abajo como una escalera, y quedó amarillo y quemado. (Wilken 1992, notas de campo).

De acuerdo con la kumiai Gloria Castañeda, el creador trató de extraer el sol de diferentes partes de su cuerpo, finalmente logrando sacarlo a 
través de su una. Una vez afuera, estaba muy caliente, asf́ que lo levanto hacia el cielo con un bastón, como en la version yavapai del Oeste (Wilken, notas de campo, 1994).

4) El creador viejo muere y es cremado. Durante la cremación, Coyote se roba el corazón y se lo come.

El motivo del dios moribundo es un tema universal no sólo en las mitologías de los grupos yumanos, también se encuentra como motivo dominante entre los shoshone y otros grupos del sur de California (Kroeber, citado en Álvarez de Williams, 1975). Entre los grupos considerados aquí, las diferentes versiones del cuento del dios moribundo y el robo de su corazón muestran una constancia notable. El tema es lo suficientemente fuerte para tomar diversas formas - como poema épico, como parte de la mitología del origen, un ciclo de canciones y como fragmento de cuento. Las instrucciones del dios-creador para su propio funeral sirven para informar y santificar la práctica de la cremación y de oưos rituales alrededor de la muerte, tal como la quema de todas las pertenencias personales del difunto. Puesto que el ritual que rodea la muerte es el más importante y el más elaborado entre los grupos yumanos, no sorprende que este aspecto de la mitología reciba especial atención.

Algunas de las versiones especificamente mencionan el wa keruk, una ceremonia de luto llevada a cabo por los grupos yumanos al año después de muerta la persona.

En la mayoría de las versiones, el dios-creador mayor padece de una enfermedad prolongada y fallece. Antes de morir, explica cómo llevar a cabo la cremación y le dice a la gente que se cuide del coyote. De acuerdo al Hualapai Paul Talieje:

...madera ellos recogían, recogian y recogian, hicieron esto e hicieron el montón alto.

Ahí, ahí, en lo alto.

ahí, ellos lo acostaron, ellos lo acostaron ahi.

Todo lo que poseía, todo lo que le pertenecía.

Todas sus pertenencias, en el suelo hicieron un fuego...

Entonces, ahí mismo, en el lugar èl dijo.

El, Judabah dijo, encendedor de fuego, que necesitamos..

El dijo, Primo Coyote, ve con el cuidador del fuego...

Bien, entonces vas; has dicho que eres igual a cuatro bombres

Ve, corre, ve;

... cuando llegues ahi,

pregunta por el encendedor de fuego y tráelo.

Entonces podemos cremarlo, él dijo.

Cuando te vayas, nunca, nunca voltees... 
ve hacia adelante y vete.

Salió con gran velocidad, y se fue.

"Atrás de mí, echaré un vistazo, miraré."

Una nube de humo vio en esa dirección;

Ahí se regresó...

Ellos cremaron a este bombre, la carne se quemó hasta ser ceniza...

Eso fue exactamente lo que pasó, así paso al cuerpo,

el cuerpo se había quemado, pero,

El corazón, pulmones, hígado, permanecieron en las brasas calientes.

Estaban todavia ardiendo, pero

de algún lugar, el Primo Coyote apareció,

los órganos que permanecían en las brasas.

a ese, lo agarró.

Por eso es que lo van a matar, ellos siempre dicen.

Ése, su nariz está ennegrecida y hacia arriba, ellos dicen.

Ése, él aprisionó el corazón ardiendo en su boca.

(Hinton, 1984:29-32).

La versión de Talieje es contada como un poema épico. Aunque otras partes de la narración son específicas a la versión hualapai, los detalles de la cremación y el robo del corazón de Coyote coincide con la mayoría de las versiones yumanas de la primera cremación, como en la versión siguiente de los yavapai del oeste.

Después de su muerte cavaron un borno, usando madera muerta y yerbas, pero no tenian fuego. No tenían modo de hacer el fuego. Se preguntaban entre ellos. Trataron de flechar una montaña con un pedernal, para lograr una chispa. Antes de que empezaran a tirar con el pedernal ellos aconsejaron a Coyote (kisar) que fuera a cierta montaña a tomar el fuego, porque cuando disparaban la flecha podían ver humo en la montaña. Así que él fue por el fuego. Antes de alcanzar la montaña miró para atrás y vio que empezó a salir humo de la pira. Así que se dijo a sí mismo, Ya sé que están quemando al bombre muerto ahora. No tendré oportunidad de verlo antes de que se acabe de quemar. Se regresó tan rápido como podía correr.

La gente sabía que estaba por venir, así que hicieron un gran anillo alrededor de la pira y trataron de que el fuego quemara más rápido antes de que llegara Coyote. Coyote llegó antes de que el corazón se quemara. No podía cruzar el anillo de gente. Corría alrededor y alrededor preguntando: ¿Dónde me pararé a aullar?. Finalmente encontró a los tejones que eran más bajos que los otros. Saltó sobre la gente tejón y cogió el corazón. Girando rápido salto sobre los tejones y escapó. Se comió el corazón (Gifford, 1933:402-403). 
Estos mismos elementos básicos tienen eco en las versiones yavapai del noreste (Gifford, 1933:350-351) y yavapai del sur del mito. En la última versión, tomada de un texto titulado "Cómo empezó todo y cómo aprendimos a vivir correctamente", el coyote salta sobre la tortuga en vez de los tejones.

Cuando el hombre viejo murió, la gente mandó lejos al Coyote. Queman al hombre muerto y todos se paran alrededor. Pero el coyote voltea y ve el humo. Así que corre de regreso. La gente se para alrededor porque saben que el Coyote quiere el corazón. Es por eso que lo bloquean. El fuego quema el cuerpo. Sólo queda una pequeña pieza. El Coyote viene y corre alrededor atrás de la gente, ¡Déjenme pararme adentro y llorar! ¡Déjenme pararme adentro y llorar! El Coyote corre alrededor, corre alrededor, corre alrededor, y pronto ve un hombre pequeño y bajo, la tortuga. Salta sobre él. El corazón casi se ha quemado. Queda una piececita. El coyote la agarra, corre y salta sobre el mismo hombre pequeño. Se come el corazón también (Khera, 1979:41).

En una versión kumiai del mito, la cremación del dios-creador es recordada como habiendo tenido lugar fuera del territorio histórico kumiai.

\begin{abstract}
Después de una larga enfermedad murió Tcipakomat y su cadáver fue incinerado para que el coyote no se lo comiera. Aquella fue la primera cremación, y fue hecha en el lado este del Río Colorado. Mosca azul (Maskumpu tai) encendió el fuego. Durante el acto, gentes y animales se colocaron en círculos alrededor del cadáver, pero el coyote saltó sobre ellos y salvó del fuego el corazón de Tcipakomat y huyó con él hacia el este. En todo el camino, donde fue cayendo sangre del corazón, dejó manchas rojas en las piedras (Bendímez, 1991:75).
\end{abstract}

En muchas de las versiones, el acto de comerse el corazón del creador conlleva alguna forma de transformación, como en la versión hualapai donde el calor del corazón ardiendo quema la nariz del coyote y la deja torcida hacia arriba, y en el ejemplo previo donde la sangre del corazón deja manchas rojas en las piedras. Aunque no hay usualmente una explicación para el deseo del coyote de comerse el corazón, parece haber una suposición implícita de que "el robo del corazón se relaciona, como en otras culturas, con el deseo del coyote de adquirir la fuerza y las cualidades [del creador]" (Bendímeż, 1991:82). Este proceso de transformación es evidente en el mito cucapá, que toma la forma de un ciclo de canciones llamado "sa' wi" o zopilote. Las canciones dicen la historia de la creación de la tierra y la muerte del "superhombre". Las frases siguientes son las interpretaciones de las letras de varias canciones de este ciclo. 
El superhombre muere. Mientras ardía la pira crematoria, Coyote viajaba bacia aquel lugar... Los animales formaban un círculo alrededor del fuego. El zopilote pidió a todos se pararan firmemente. conservándose lo más cerca posible uno del otro. Había un animal muy pequeñito, Coyote lo sabía y planeaba romper el círculo en aquel lugar. Al llegar coyote pidió a los animales del círculo que por favor se separaran para tener el lugar por donde entrar a darle cuatro vueltas a la fogata, después de lo cual encontraria un lugar donde detenerse a llorar (a la usanza de los asistentes a ceremonias de cremación). Uno a otro animal, susurrando entre sí se dijeron que deberian guardar sus posiciones y no admitirlo. Coyote planeaba arrancar el corazón del superhombre, pensando que el fuego no lo consumiria.

Los animales se mantuvieron en formación cerrada, pero Coyote saltó sobre la hilera, se apoderó del corazón del superhombre que el fuego aún no consumía, saltó hacia afuera en el mismo lugar por donde había entrado y corrió rápidamente hacia el Este. Cuando Coyote había salvado una gran distancia, se paró en una montaña, devoró el corazón y quedó inconsciente a causa del hechizo que se apoderó de él. Inmediatamente murió (Álvarez, 1975:85-95).

Para el Coyote, "muerte" es usualmente una forma de transformación, como en el cuento paipai "Las hijas del Tecolote", en donde el primer coyote muere, y pedacitos de sus huesos son transformados en la raza de coyotes (Wilken, 1982:10). El paipai Benito Peralta dice de un coyote que se come el corazón humano no como mito del origen sino como una fábula sobre cómo el coyote se convirtió en un bromista.

Cuando se moria uno, pa quemarlo juntaban bastante leña sin que se diera cuenta el Coyote. Entonces dijeron nos hace falta lumbre, no tenemos y usted Coyote es bueno para andar. lo mandaron a un lugar lejos y ahí va el Coyote, pero como siempre va por los cerros altos, de vez en cuando volteaba porque si divisaba humo quiere decir que ya le prendieron y éste se regresa. Cuando la gente ya calcula que andaba muy lejos el coyote entonces le prenden.

Pero dicen que el corazón humano es muy duro para quemar y tarda, pues tienen que estar rodeando al cuerpo y protegerlo del coyote, pero siempre en un descuido diecn que encuentra una falla o algún chaparrito, y allí brinca o si no por entre las piemas, y agarra el corazón y se pinta, arranca y así por eso lo cuidan mucho a la hora de quemar el cuerpo.

Debe ser muy sabrosísimo para él, yo creo que si, por eso el Coyote es muy vivo (Wilken, notas de campo,1993).

El detalle del coyote robando el corazón humano de una pira funeraria y devorándolo puede asumirse que antecede al cambio de prácticas funerarias entre los yumanos de cremación a entierro, un cambio que acompañó 
la era del contacto con culturas europeas. Todo el paquete de detalles examinado arriba, con su sitio importante dentro de las mitologías del origen de los grupos yumanos, pueden muy bien retrotraerse a un tiempo cuando los ancestros de los grupos yumanos actuales vivían más próximos entre ellos y hablaban una sola lengua.

Por supuesto que es necesaria mucha más investigación para apoyar esta hipotesis: investigación arqueológica puede ayudarnos a entender mejor los orígenes de los yumanos; más investigación dentro de la etnografía existente, especialmente de los grupos yumanos no considerados aquí (los quechanos, los mojave, los maricopa y otros ahora extintos), así como comparaciones con grupos no lingǘsticamente relacionados pueden ayudarnos a entender las influencias de fuera de la región yumana; el análisis lingüístico de los mitos puede también proveer de valiosas pistas, especialmente puesto que la naturaleza conservadora de la tradición oral frecuentemente retiene formas arcaicas perdidas con el uso cotidiano. Finalmente, es necesaria investigación adicional que tome en consideración a la región yumana como un todo, en vez de separar arbitrariamente a los grupos yumanos de México y de Estados Unidos, con el propósito de unir de nuevo los fragmentos dispersos de miles de años de historia indígena.

\section{BIBLIOGRAFÍA}

ÁLVAREZ de Williams, Anita. 1975. "Primeros pobladores de Baja California". Talleres litográficos del gobierno del Estado.

- 1987. "Los cucapá y su medio ambiente". Estudios Fronterizos, Vol. V, núm. 14. Instituto de Investigaciones Sociales, UABC.

ÁLVAREZ, Ila. 1978. "Document No. 35: A Mapp Maker's Story of His Journey from San Diego to the Sea of Cortes", En: Brand book, núm. 5 San Diego Corral of the Westerners. San Diego.

BENDIMEZ Patterson, Julia. 1985. "Algunas consideraciones sobre la arqueología de Baja California”. Meyib6. Vol. II, núm. 5.

- 1987. "Antecedentes históricos sobre los indígenas de Baja California". Estudios Fronterizos. Vol. V, no. 14. Instituto de Investigaciones Sociales, UABC.

- 1989. "Historia Oral: Benito Peralta de Santa Catarina, comunidad paipai". Cuadernos de Ciencias Sociales. Serie 4, núm.4, IIS-UABC.

- 1991. "Los mitos como parte del sistema de creencias de los indígenas de Baja California". Estudios Fronterizos, núm. 24-25. Instituto de Investigaciones Sociales, UABC. 
CLAVIGERO, Francisco Javier. 1937. "The History of (Lower) California". Stanford University Press. Traducido del italiano y editado por Sara E. Lake y A.A. Gray.

GIFFORD, E.W. 1933. Northeastern and Western Yavapai Myths. p. 347-414, Journal of American Folklore, v. 36.

HENDRICKS, William O. 1976. "The Lost Cucapa Reservation". Pacific Coast Archaeological Society Quarterly, Vol. 12 (1) Costa Mesa. HINTON, Leanne y Watahomigie, Lucille J., 1984. Spirit Mountain. An Anthology of Yuman Story and Song. Sun Tracks-University of Arizona Press/Tucson, Arizona. Vol. 10.

HOVENS, Pieter. 1991. "The Origins of Anthropology in Baja California: The Fieldwork and Excavations of Herman Ten Kate in 1883". Pacific Coast Archaeological Quarterly, Vol.27, núm. 4, Costa Mesa.

KELLY, William. 1977. Cocopa Ethnography. Anthropological papers of the University of Arizona. Vol.29.

KHERA, Sigrid. 1979. "The Yavapai of Fort McCowell: An Outline of their History and Culture". 2da. ed. Fountain Hills, Arizona.

KOWTA, Makota. 1984. "The Layer Cake Model of Baja California Prehistory Revised: An Hypothesis". Pacific Coast Archaeological Society Quarterly, Vol. 20, núm.1, Costa Mesa.

KROEBER, Alfred L., Ed. 1935. "Walapai ethnography". American Anthropological Association memoirs. Núm. 42.

LAYLANDER, Don. 1985. "Some Linguistic Approaches to Sounthern California's Prehistory". San Diego State University Cultural Resource Managgement Casual paper 2 (1).

- 1991. "Organización comunitaria de los yumanos occidentales: una revisión etnográfica y prospecto arqueológico". Estudios Fronteri$z o s$, Instituto de Investigaciones Sociales, UABC.

- 1993. (Ed.) "Research Issues in San Diego Archaeology". San Diego County Archaeological Society.

LEÓN PORTILLA, Miguel. 1987. "Los Pobladores Indígenas", en Visión Historica de la Frontera Norte de México, Tomo I. Coord. David Piñera. UABC, México.

MASSEY, William. 1966. "Archaeology and Ethnohistory of Lower California". En: Archaeological frontiers and external connections, Handbook of Middle American Indians. Vol.4.

MICHELSEN, Ralph. 1991. "La territorialidad del indígena americano de la tierra alta del norte de la Baja California". Estudios Fronterizos, Núm.24-25, Instituto de Investigaciones Sociales, UABC. 
MIXCO, Mauricio J. 1977. "The innovation of/h, hw/ in Kiliwa". International Journal Of American Linguistics, Vol. 43, núm.1.

- 1983. "Kiliwa Texts: When I Have Donned my Crest of Stars". University of Utah Anthropological Papers 107.

MORIARTY, James R. 1966. “Culture Phase Divisions Suggested by Typological Change, Coordinated with Stratigraphically Controlled Radiocarbon Dating at San Diego". Anthropological Journal of Canada, Vol.4, núm.4.

- 1970. "A Synthesis of the Pre-history of Baja California". Pacific Coast Archaeological Society Quarterly, Vol. 6, núm. 1.

OWEN, Roger C. 1962. "The Indians of Santa Catarina, Baja California, Mexico: Concepts of Disease and Curing". Tesis de doctorado. Departament of Anthropology, University of California, Los Ángeles.

ROGERS, Malcolm. 1936. "Yuman Pottery Making", San Diego Museum Papers, núm. 2.

- 1945. "An Outline of Yuman Prehistory". Southwestern Journal of Anthropology. Vol. 1, núm. 2.

- 1966. Anciet hunters of the Far West, Copley Book. San Diego, California.

SHIPEK, Florence, 1982. "Kumeyaay Socio-Political Structure". Journal of California and Great Basin Anthropology, 4:296-303.

- 1987. Pushed into the Rocks: Southern California Indian Land Tenure, 1769-1986, University of Nebraska Press, Lincoln.

- 1989. "An Example of Intensive Plant Husbandry: the Kumeyaay of Southery California". En: Foranging and Farming. The evolution of Plant Explotation. Editor, David Harris y Gordon C. Hillman. Institute of Archaeology University College London.

- 1993. "Kumeyaay Plant Husbandry: Fire, Water, and Erosion Control Systems". En: Before the Wilderness: Environmental Management by Native Californians. Thomas C. Blackburn y Kat Anderson (eds.). Ballena Press.

VANCAMP, GenaR. 1979." Kumeyaay Potterty: Paddle and Anvil Techniques of Southem California". Socorro, Nuevo México, Ballena Press.

WILKEN, Mike. 1982. "Los Paipai de Baja California: Tradiciones y Cambios". Association Cultural de las Califomias, xx Simposio de la Baja California. Tecate, B.C.

- 1987. "The Paipapi Potters of Baja California: A Living Tradition". Anthropology of the Americas MASTERKEY. Vol. 60, núm. 4.

- 1992. "Baja's Paipai Indians: People from an Ancient Time". Baja Explorer, Vol. 2, núm. 6, nov.dic. San Diego. 